\title{
A CASA DAS SETE MULHERES
}

\author{
Cláudia Danielle de Andrade Ritz*
}

\begin{abstract}
RESUMO
Este artigo propõe uma reflexão sobre a violência doméstica experienciada por sete mulheres pentecostais. As mulheres, de pertença pentecostal, ao experienciarem a violência doméstica, trazem consigo elementos simbólicos próprios de sua crença e religião. Dessa forma, objetivamos a análise da violência doméstica experienciada por muIheres pentecostais, considerando as relações de gênero, de poder e o discurso religioso, para identificação dos aspectos sociorreligiosos presentes. Como metodologia, realizamos pesquisa exploratória: referencial teórico e pesquisa de campo mediante entrevistas com questionário estruturado. Acerca do resultado, faremos a exposição preliminar dos dados qualitativos em percentuais e textos, mediante análise de discurso, explanando os aspectos sociorreligiosos identificados na violência doméstica em estudo.

Palavras-chave: Violência doméstica. Relações de gênero. Pentecostais. Dados qualitativos da pesquisa de campo.
\end{abstract}

\section{THE HOUSE OF THE SEVEN WOMEN}

\begin{abstract}
This article proposes a reflection on the domestic violence experienced by seven Pentecostal women. Women belonging to Pentecostal denomination, who experience domestic violence, carry symbolic elements of their own beliefs and religion. In this way, the aim is to analyze the domestic violence experienced by Pentecostal women, considering gender and power relations, as well as religious discourse, in order to identify the existing socio-religious aspects. As metho-
\end{abstract}

* Mestranda em Ciências da Religião pela Pontifícia Universidade Católica de Minas Gerais (PUC-MG). Bacharela em Direito pela Pontifícia Universidade Católica de Minas Gerais (PUC-MG). Especialista em Direito do Trabalho pela Universidade Cândido Mendes. Graduanda em Teologia pelo Centro Universitário Izabela Hendrix. 
dology, we conducted exploratory research: theoretical reference and field research through interviews with structured questionnaire. About the result, we will present the qualitative data in percentages and texts, through discourse analysis, explaining the socio-religious aspects identified in the domestic violence under study.

Key-words: Domestic violence. Gender Relationships. Pentecostal. Qualitative data from field research.

\title{
LA CASA DE LAS SIETE MUJERES
}

\begin{abstract}
RESUMEN
Este artículo propone una reflexión sobre la violencia doméstica experimentada por siete mujeres pentecostales. Las mujeres de pertenencia pentecostal, al experimentar la violencia doméstica, traen consigo elementos simbólicos propios de su creencia y religión. De esta forma, objetivamos el análisis de la violencia doméstica experimentada por mujeres pentecostales, considerando las relaciones de género, de poder y el discurso religioso, para identificar los aspectos sociorreligiosos presentes. Como metodología, realizamos investigación exploratoria: referencial teórico e investigación de campo mediante entrevistas con cuestionario estructurado. Sobre el resultado, haremos la presentación preliminar de los datos cualitativos en porcentajes y textos, mediante análisis de discurso, explicando los aspectos sociorreligiosos identificados en la violencia doméstica en estudio.
\end{abstract}

Palabras clave: Violencia doméstica. Relaciones de género. Pentecostales. Datos cualitativos de la investigación de campo.

\section{INTRODUÇÃO}

Nossa abordagem neste artigo será acerca da violência doméstica experienciada por sete mulheres pentecostais. A pesquisa foi exploratória qualitativa, composta por referencial teórico e entrevistas com questionário estruturado, cujos dados foram trabalhos a partir da análise de discurso foucaultiana.

A respeito da natureza qualitativa da pesquisa em estudos de feminismo e gênero, Uwe Flick (2009, p. 23) pondera: “a pesquisa quantitativa normalmente ignora as vozes femininas, [...] no entanto, a pesquisa qualitativa permite que as vozes das mulheres sejam ouvidas e que os objetivos concretizados". 
A opção pelo uso de questionário estruturado nas entrevistas foi oportuna, pois partiu de questionários idênticos, logo, as peculiaridades decorrem exclusivamente das respostas de cada entrevistada, como ensina João Bosco Lodi (1974).

A seleção das entrevistadas foi intencional, afinal, foi necessário que as mulheres pentecostais que tenham experienciado violência doméstica se dispusessem a ser entrevistadas e compartilhar conosco suas experiências. Por conseguinte, a amostragem não foi probabilística. Segundo Fauze N. Mattar (1996, p. 132), “a amostragem não probabilística é aquela em que a seleção dos elementos da população para compor a amostra depende ao menos em parte do julgamento do pesquisador ou do entrevistador no campo". Ademais, recorrendo aos ensinamentos de Marina de Andrade Marconi e Eva Maria Lakatos (2012, p. 15), "propomos a delimitação dos limites da investigação a partir do recorte de tema e ainda, da extensão". ' As entrevistas foram realizadas em fevereiro de $2017^{2}$ individualmente e exclusivamente pela pesquisadora, com sete mulheres pentecostais que experienciaram a violência doméstica. ${ }^{3}$

Essa dinâmica favoreceu a interação entre pesquisadora e entrevistada, bem como, a observação das expressões faciais e corporais, além dos discursos verbalizados, nos termos conceituados por Tereza Maria Frota Haguette (1997). As percepções citadas favoreceram a aplicação da análise de discurso foucaultiana aos discursos, o qual não foca as estruturas linguísticas. Acerca da análise de discurso foucaultiana, Marina de Andrade Marconi e Eva Maria Lakatos (2012, p. 304) explicam que: "tem como foco as questões ligadas à crítica, à ideologia, e ao poder

Segundo o Censo 2010, realizado pelo Instituto Brasileiro de Geografia e Estatística - IBGE, mais de $22,2 \%$ da população brasileira se declara evangélica, demonstrando aumento em relação ao levantamento de 2000, quando representavam 15,4\%. Dos 22,2\% de evangélicos, uma porcentagem de $13,3 \%$ se declarou pentecostal e a maioria desse índice é composta por mulheres.

2 Previamente, obtivemos a autorização do CEP PUC MINAS, sob o CAAE 59542416.0000.5137, em 25 outubro de 2017. Todas as participantes assinaram previamente o Termo de Consentimento Livre e Esclarecido e assinaram ao final o questionário, validando as informações.

3 Entrevistas efetuadas em particular com cada entrevistada, em dia, horário e local designado por elas. Estava vedado a realização nas igrejas e na presença dos cônjuges, para evitar constrangimentos e "ruídos nas vozes das mulheres". 
do que nas outras versões". Corroborando, Martin W. Bauer e George Gaskell $(2002,46)$ esclarecem que: "esta via da análise de discurso estará associada ao pós-estruturalismo, ${ }^{4}$ pois não se interessará nos detalhes dos textos falados e escritos, mas em olhar historicamente os discursos". Nesse sentido, Michel Foucault (2007)5 pondera:

Os discursos são práticas que formam sistematicamente os objetos de que falam. Certamente os discursos são feitos de signos; mas o que fazem é mais que utilizar esses signos para designar coisas. É esse "mais" que os torna irredutíveis à língua e ao ato da fala. E esse "mais" que é preciso fazer aparecer e que é preciso descrever (Michel FOUCAULT, 2007a, p. 55).

Frente ao exposto, e como instruído por Marina de Andrade Marconi e Eva Maria Lakatos (2012, p. 4), a metodologia de caráter exploratório qualitativa permitiu à investigadora aumentar sua experiência em torno do problema - violência doméstica experienciada por mulheres pentecostais. Corroborando, Writsman Cook Selltiz (1967) ensina que a pesquisa exploratória expande a percepção e o alcance do problema a ser pesquisado, o que favoreceu nossa análise de discurso foucaultiana ${ }^{6}$ empreendida a partir dos dados colhidos nas entrevistas. As referências são balizadoras e dialogam com os dados coletados em campo. Para fins didáticos, a apresentação em percentual seguirá com o número absoluto correlato entre parêntese seguido da letra a.

Registramos que os dados apresentados não ambicionam generalizações de qualquer natureza, tampouco objetivam retratar todo o cenário pentecostal ou de violência doméstica. Contudo, acreditamos que ampliaremos nosso conhecimento sobre a violência doméstica experienciada por mulheres pentecostais, a partir das vozes das mulheres entrevistadas e das respectivas análises.

4 Conjunto de investigações filosóficas contemporâneas, especialmente Foucault [1926-1984] e Derrida [1930-2004]. Para maiores detalhes, ver https://periodicos.unifap.br/index.php/estacao/ article/view/1742. Acesso em 28 nov. 2017.

5 FOUCAULT, Michel. A Ordem do Discurso: aula inaugural no Collège de France. Pronunciada em 2 de dezembro de 1970, 15. ed. São Paulo: Loyola, 2007.

6 Michel Foucault apresenta na aula inaugural no Collège de France, pronunciada em 2 de dezembro de 1970, intitulada A Ordem do Discurso (2007). 


\section{A VIOLÊNCIA DOMÉSTICA EXPERIENCIADA PELAS ENTREVISTADAS}

Consideramos oportuno tratarmos da violência doméstica experienciada pelas entrevistadas, incluso suas formas e incidências. Para fins de consideração sobre os conceitos e as formas de violência doméstica, adotou-se a classificação da Lei $n^{\circ}$. 11.340, de 7 de agosto de 2006 (Lei Maria da Penha), ${ }^{7}$ em especial dos artigos $6^{\circ}$. e $7^{\circ}$.

As sete mulheres entrevistadas relataram experiências com mais de uma forma de violência, algumas acontecendo concomitantemente. Assim, passamos à apresentação dos dados.

Tivemos $100 \%$ (7a.) de relato de incidência de violência moral/verbal, essa forma de violência foi tratada conjuntamente pelas entrevistadas; $71 \%$ (5a.) de violência física e 57\% (4a.) de violência sexual. Frente aos índices, percebemos que as violências morais/verbais perpassaram todas as relações matrimoniais em tema 100\% (7a.), precedendo às outras formas de violência, ou, ocorrendo concomitante com as violências física e sexual. Conforme Rita Laura Segato (2010): ${ }^{8}$

Enquanto as consequências da violência física são geralmente evidentes e denunciáveis, as consequências da violência moral não o são. É por isso que, apesar do sofrimento e do dano evidente que a violência física causa a suas vítimas, ela não constitui a forma mais eficiente, nem a mais habitual de reduzir a autoestima, minar a autoconfiança e desestabilizar a autonomia das mulheres (Rita Laura SEGATO, 201, p. 113, tradução do autor).

Acerca da violência física preconizada em 71\% (5a.), a alta incidência requer alerta. Esse modo de violência é grave e revela ousadia e destemor por parte do agressor, afinal, não raramente deixa provas nos corpos. Além disso, a violência física beira perigosamente sua forma

Disponível em http://www.planalto.gov.br/ccivil_03/_ato2004-2006/2006/lei/111340.htm. Acesso em 29 nov. 2017.

8 Mientras las consecuencias de la violência física son geralmente evidentes y denunciables, las consequências de la violência moral no lo son. Es por esto que, a pesar del sufrimiento y del daño evidente que la violência física causa a sus víctimas, ella no constituye la forma más eficiente ni la más habitual de reducir la autoestima, minar la autoconfianza y desestabilizar la autonomia de las mujeres. 
ainda mais agravada que é o feminicídio. ${ }^{9}$ De acordo com o relatório final da Comissão Parlamentar Mista de Inquérito do Senado (CPMI-VCM) de 2013:10 "o feminicídio é a instância última de controle da mulher pelo homem: o controle da vida e da morte. Ele se expressa como afirmação irrestrita de posse, igualando a mulher a um objeto, quando cometido por parceiro ou ex-parceiro; [...]”. A esse respeito, a especialista contratada pela ONU Agnes Callamard (2017), ${ }^{11}$ corrobora:

A importância de reconhecer ataques de gênero como uma violação aos direitos humanos, e assassinatos domésticos, como uma forma de execução arbitrária. O fato é que, o gênero tem um papel absolutamente central em determinar a habilidade das pessoas de usufruir seus direitos humanos socialmente, e o direito à vida em particular. A misoginia persiste em todos os níveis da sociedade [...]. O direito à vida não é apenas uma questão de direitos civis e políticos, é também uma questão de direito ao desenvolvimento e aos direitos econômicos, sociais e culturais (Agnes CALLAMARD, 2017).

Nesse sentido, há violação de direitos humanos, mas há também perigo de morte, que afeta toda a sociedade e não apenas as mulheres, como marca das discrepâncias nas relações de gênero. Trata-se de um "generocídio".

A violência sexual foi pontuada por $57 \%$ (4a.) das entrevistadas. Esse tipo de violência conotou nítido constrangimento ao ser relatado. Por conseguinte, era imediatamente amenizado pelas entrevistadas com ponderações sobre a conjunção carnal ser inerente ao casamento. Embora haja essa tentativa de justificação, fato é que as entrevistadas que pontuaram a ocorrência da violência sexual tinham consciência de que o ato sexual não era desejado por elas no momento e nas circuns-

9 Lei 13.104/2015 http://www.planalto.gov.br/ccivil_03/_Ato2015-2018/2015/lei/L13104.htm. Acesso em 30 nov. 2017.

10 Disponível em https://www12.senado.leg.br/institucional/omv/entenda-a-violencia/pdfs/relatorio-final-da-comissao-parlamentar-mista-de-inquerito-sobre-a-violencia-contra-as-mulheres. Acesso em 27 nov. 2017.

11 CALLAMARD, Agnes. Entrevista Agnes Callamard [S.I.]: ONU Brasil, jun. 2017. Entrevista concedida à ONU. Disponível em https://nacoesunidas.org/violencia-domestica-e-uma-forma-de-execucao-arbitraria-diz-especialista-independente-da-onul. Acesso em $1^{\circ}$. nov. 2017. 
tâncias ocorridas. O artigo $7^{\circ}$., inciso III, da Lei 11.340/2006, conceitua a violência sexual da seguinte forma:

III - a violência sexual, entendida como qualquer conduta que a constranja a presenciar, a manter ou a participar de relação sexual não desejada, mediante intimidação, ameaça, coação ou uso da força; que a induza a comercializar ou a utilizar, de qualquer modo, a sua sexualidade, que a impeça de usar qualquer método contraceptivo ou que a force ao matrimônio, à gravidez, ao aborto ou à prostituição, mediante coação, chantagem, suborno ou manipulação; ou que limite ou anule o exercício de seus direitos sexuais e reprodutivos (Lei 11.340/2006, art. $7^{\circ}$. III, grifos do autor).

Tal ato sexual se configura como uma apropriação não desejada dos corpos das mulheres, exercida pelos cônjuges. Essa prática não deve ser validada pelo registro civil de casamento entre as partes. A dominação sexual é a manifestação de uma forma de poder, o poder sobre os corpos, sobre o desejo, sobre a sexualidade e o livre exercício da atividade sexual. Para Pierre Bourdieu (2017, p. 36), “[...] ato sexual em si é concebido pelos homens como uma forma de dominação de apropriação, de "posse" [...]". Portanto, quando exercido mediante constrangimento, deflagra violação e manifestação de posse ${ }^{12}$ sobre o bem simbólico e peculiar da humanidade - os corpos.

No Mapa da Violência 2015 Homicídio de Mulheres no Brasil, da autoria de Júlio Jacobo Waiselfisz (2015), ${ }^{13}$ considerando as formas de violência em análise e o cenário brasileiro temos:

A violência física é, de longe, a mais frequente, presente em 48,7\% dos atendimentos, com especial incidência nas etapas jovem e adulta da vida da mulher, quando chega a representar perto de $60 \%$ do total de atendimentos. Em segundo lugar, a violência psicológica, presente em $23,0 \%$ dos atendimentos em todas as etapas, principalmente da

12 Para estudo sobre esse tema ver: SEGATO, Rita Laura. Las estruturas fundamentales de la violencia: ensayos sobre género entre la antroplogía, el psicanálisis y los derechos humanos. Argentina: Prometeos, 2010.

13 WAISELFISZ, Julio Jacobo. BRASIL, Mapa da Violência. Homicídio de mulheres no Brasil 2015, p. 23. Disponível em http://www.mapadaviolencia.org.br/pdf2015/MapaViolencia_2015_mulheres. pdf. Acesso em 27 set. 2017. 
jovem em diante. Em terceiro lugar, a violência sexual, objeto de $11,9 \%$ dos atendimentos, com maior incidência entre as crianças até 11 anos de idade (29,0\% dos atendimentos) e as adolescentes $(24,3 \%)$ (Jacobo WAISELFISZ, 2015, p. 23).

Assim, ao compararmos os dados colhidos nas entrevistas e os índices do Mapa já citado, percebemos que há convergência. Destacamos que $100 \%$ das mulheres entrevistadas apontaram o cônjuge como autor da prática costumeira de violência doméstica. A predominância da autoria do agressor e a faixa etária (entrevistadas com idades entre 40 a 53 anos) também estão alinhadas ao referido Mapa de Júlio Jacobo Waiselfisz (2015, p. 48) "para as jovens e as adultas (de 18 a 59 anos de idade), o agressor principal é o parceiro ou ex-parceiro [...]".

Registramos que, em todos os casos pesquisados, a violência doméstica teve início após o casamento. O casamento parece ter desencadeado um pressuposto equivocado de propriedade, no qual as mulheres se tornam esposas e compulsoriamente são tidas como bens adquiridos pelos cônjuges. Nesses pressupostos, a dignidade humana é comprometida e violações se tornam costumeiras.

Além disso, a entrevistada Rute comentou que suportou violência física cometida pela mãe antes do casamento "apanhava muito". Esse dado também condiz com o Mapa da Violência 2015, de Júlio Jacobo Waiselfisz (2015, p. 48), "82\% das agressões a crianças do sexo feminino, de $<1$ a 11 anos de idade, que demandaram atendimento pelo Sistema Único de Saúde (SUS), partiram dos pais - principalmente da mãe, que concentra 42,4\% das agressões". Ao menos para Rute, experiências de violência ocorreram antes do casamento praticadas pela mãe e pós casamento pelo cônjuge. Houve ainda um apontamento de violência de $29 \%$ das entrevistadas que residem em casas situadas "nos fundos" dos imóveis das sogras, e isso resultaria em violências verbal/moral constantes. A ausência de casa própria, reflexo de aspectos sociais do Brasil, favorece violências pelas sogras e pelos maridos, num cenário de conflitos diários.

Identificamos $100 \%$ de reincidência na violência doméstica praticada pelos cônjuges, e tal evento revela alguma participação das mulheres que experienciam, na medida em que não há o elemento da surpresa. A 
reincidência denuncia também a impunidade em face ao agressor. Além disso, aponta potencial de agravamento nas formas de violência, como citado no Mapa da violência no Brasil, de Júlio Jacobo Waiselfisz (2015).

A impunidade é amplamente prevalecente nos homicídios dolosos em geral, com muito mais razão, pensamos, deve ser norma nos casos de homicídio de mulheres. A normalidade da violência contra a mulher no horizonte cultural do patriarcalismo justifica, e mesmo "autoriza" que o homem pratique essa violência, com a finalidade de punir e corrigir comportamentos femininos que transgridem o papel esperado de mãe, de esposa e de dona de casa (Jacobo WAISELFISZ, 2015, p. 75).

Ao comentar sobre as características observadas nos cônjuges no momento da violência, as entrevistas citaram características combinadas. Logo, os percentuais estão cumulados: perfil violento $43 \%$; irritado $43 \%$; alcoolizado 43\%; possessão demoníaca 43\% e com razão 57\%. Destacamos a princípio, 57\% declararem que "o cônjuge estava com razão". Essa afirmativa das entrevistadas corresponsabiliza as próprias mulheres pela violência doméstica experienciada.

Débora (2017) eu reclamo da bebida, ele é alcoólatra.

Raquel (2017) ele chega embriagado e eu tiro satisfação.

Ana (2017) eu o agredi e ele me agrediu [fisicamente].

Raabe (2017) eu questiono a interferência da mãe dele.

Notamos, da síntese dos discursos, que os cônjuges haviam sido "provocados" por algum questionamento delas. Na inteligência das falas, as mulheres não deveriam ousar ter vozes. Evidente que, nesses discursos, percebemos um traço de submissão social das mulheres.

Além disso, a irritação foi citada, e sabidamente, a ira é um sentimento humano, mas não deve ser tida como justificativa para o agir violentamente contra outrem. Ademais, as entrevistadas que mencionam o perfil violento dos cônjuges parecem assimilar tal conduta como aceitável, se não, "normal”. Parece que a associação de agressividade ao gênero masculino goza de certa beatificação social, fortalecida pelos ditos fatos históricos. Nesse aspecto, a coragem por vezes está relacionada à covardia. Segundo Pierre Bourdieu (2013): 
O que chamamos de "coragem", muitas vezes tem suas raízes em uma forma de "covardia": para comprová-lo, basta lembrar todas as situações em que, para lograr atos como matar, torturar ou violentar, a vontade de dominação, de exploração ou de opressão baseou-se no medo "viril" de ser excluído do mundo dos "homens" [...] (Pierre BOURDIEU, 2013, p. 78).

Por fim, a alegação de "possessão demoníaca" é uma afirmativa que marca perfeitamente o local de fala das mulheres - um lugar de pertença pentecostal. Essa perspectiva avança do imanente ao transcendente, e requer, por conseguinte, o agir divino.

A cadência de características percebidas pelas entrevistadas nos cônjuges em contexto de violência, conjetura a manutenção da hierarquia masculina, fundada em supostos valores sociais que ambicionam serem respeitados e preservados. Peter Berger aduz (2013, p. 23), “o homem produz valores e verifica que se sente culpado quando os transgride".

As mulheres parecem ocupar um local de culpa e de autossacrifício. Os homens o local de dominação e de exercício de poder, para manter os valores e certa ordem, dita natural, porém, foi naturalidade culturalmente. Corroborando, Ivone Gebara (2000) esclarece que:

A reflexão sobre o sacrifício nos leva a uma reflexão sobre a culpabilidade vivida pelas mulheres. O sentido dessa culpabilidade não é muito preciso, isso porque "aquilo" que se sente e que se chama culpabilidade parece um tanto difuso na vida das mulheres e condicionado pelas culturas. Trata-se de uma culpabilidade existencial com uma extensão religiosa (Ivone GEBARA, 2000, p. 137).

Assim, a partir dos depoimentos e da reflexão proposta por Ivone Gebara, consideramos como elemento imperativo o poder simbólico que, segundo Pierre Bourdieu (1989), é exercido com a cumplicidade daqueles que estão sujeitos, e, dos que exercem. Esse poder parte de uma construção social, que é respaldada por vezes pelo discurso religioso e se torna cultural. 
Acerca dos aparatos estatais: ${ }^{14}$ apoio judicial; apoio policial e casas de amparo; nenhuma dessas medidas se apresentaram eficazes na perspectiva das entrevistadas. Tivemos $86 \%$ afirmando que não levaram a violência doméstica ao conhecimento do poder judiciário, e 14\% que declararam que sim. O relato da entrevistada que buscou apoio do judiciário indica morosidade e ineficácia do Estado.

Rute (2017) a justiça foi muito lenta e o caso acabou arquivado. Eu pedi pensão alimentícia, pois uma de minhas filhas estava cursando universidade e sequer chegou a acontecer a audiência. Se um homem não respeita a família, não vai respeitar a lei.

Atualmente, há movimentos por parte do judiciário brasileiro, promovido especialmente pela presidência do STF, no intuito de agilização dos processos cuja natureza seja violência doméstica. ${ }^{15} \mathrm{~A}$ respeito do apoio da polícia, $57 \%$ das entrevistadas disseram que já buscaram esse apoio e comentaram sua experiência.

Rute (2017) várias vezes, mas, me arrependi. Me senti "violentada" pelos policiais, pela forma que fui tratada, com sarcasmo. Eu chorava, fui exposta, ultrajada e me senti culpada. Ao final, era de madrugada e chovia muito. Meu marido voltou de táxi, enquanto eu me minha filha que estava junto, voltamos de ônibus, na chuva.

Raquel (2017) ele [cônjuge] estava me agredindo e ameaçando de morte. Ainda me ameaça de morte. Na polícia, a situação não se resolveu, não mudou nada, mas foram educados.

Ana (2017) fui bem atendida. Nos orientaram a conversar e entrar em acordo ou nos separar, para não continuar na mesma situação. Se a agressão se repetisse, ele seria preso.

Notamos que, embora as experiências tenham sido diversas, não houve solução definitiva quando a polícia foi acionada. Nenhuma das entrevistadas utilizou casa de amparo, mas elas alegaram que usariam se

14 Disponível em http://www.cnj.jus.br/noticias/cnj/85066-audiencia-judicial-ajuda-mulheres-a-vencer-o-medo-de-agressores. Acesso em 8 de agosto de 2017. Acesso em 27 set. 2017.

15 Disponível em http://www.tjmg.jus.br/portal/conheca-o-tjmg/estrutura-organizacional/atendimento-a-mulher/programas-e-projetos/campanha-nacional-compromisso-e-atitude.htm. Acesso em 12 abr. 2017. 
necessário, o que conota certa contradição. Contudo, as entrevistadas afirmaram que indicariam os aparatos estatais para mulheres em situação de violência doméstica. Todas as entrevistadas disseram conhecer a Lei Maria da Penha, objetivo e aplicabilidade, sendo a mídia e os jornais os principais veículos de informação mencionados. Especificamente, Débora e Rute quiseram minuciar suas opiniões sobre a citada lei.

Débora (2017) acho que não funciona. Tem muita mulher sofrendo violência. A [mulher] morta na capa do jornal, é alguém que já sofreu muito [antes de ser assassinada].

Rute (2017) hoje sim [conheço a Lei], mas estou decepcionada, a Lei apenas instrui sobre a violência, mas não coloca fim na violência.

A respeito do sentimento de segurança em suas casas, $57 \%$ das entrevistadas disseram que não se sentem seguras nas suas casas, no entanto, $71 \%$ das mulheres se sentem seguras nas igrejas que frequentam. Essa é uma informação importante, e demonstra que a pertença pentecostal se manifesta positivamente na rotina diária das entrevistadas, como ensejadora de bem-estar, frente a uma realidade marcada pela violência.

\section{ASPECTOS SOCIAIS DA VIOLÊNCIA DOMÉSTICA EM ESTUDO}

As sete entrevistadas escolheram pseudônimos bíblicos, sendo: Débora, Glória, ${ }^{16}$ Rute, Ana, Sara e Raabe. Todas as entrevistadas eram maiores, declararam pertença pentecostal e tinham experienciado a violência doméstica após o casamento. Contudo, as entrevistadas permanecem na constância do primeiro casamento, exceto Glória, que está no segundo matrimônio (se divorciou do primeiro esposo, que era o agressor) e Rute, que está separada do marido agressor. Para melhor identificação dos perfis das entrevistadas, consideraremos o Quadro 1.

16 A entrevistada Glória se divorciou do primeiro cônjuge, matrimônio que durou 19 anos, no qual experienciou a violência doméstica e na constância do casamento teve seus dois filhos. Glória, na época, já era pentecostal, assim como seu marido, que praticava a violência. 
Quadro 1 - Perfil das entrevistadas

\begin{tabular}{|c|c|c|c|c|c|c|c|c|}
\hline 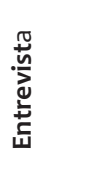 & 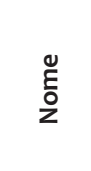 & $\begin{array}{l}\frac{\pi}{0} \\
\frac{2}{00}\end{array}$ & 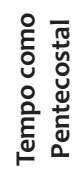 & 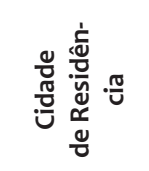 & 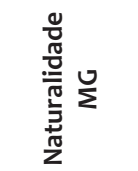 & $\begin{array}{l}\frac{\pi}{T} \\
\text { Tㅁ }\end{array}$ & 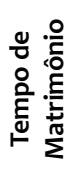 & 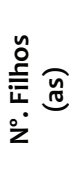 \\
\hline 11 & $\begin{array}{l}\text { Débo- } \\
\text { ra }\end{array}$ & $\begin{array}{l}\text { Batista Independen- } \\
\text { te, em Contagem }\end{array}$ & 222 & Contagem & $\begin{array}{l}\text { Belo Hori- } \\
\text { zonte }\end{array}$ & 553 & 330 & 44 \\
\hline 22 & Glória & $\begin{array}{l}\text { Assembleia de } \\
\text { Deus, em Belo } \\
\text { Horizonte }\end{array}$ & 222 & $\begin{array}{l}\text { Belo Hori- } \\
\text { zonte }\end{array}$ & Pescador & 448 & 119 & 22 \\
\hline 33 & Rute & $\begin{array}{l}\text { Batista Indepen- } \\
\text { dente, em Belo } \\
\text { Horizonte }\end{array}$ & 221 & Sabará & $\begin{array}{l}\text { Belo Hori- } \\
\text { zonte }\end{array}$ & 553 & 332 & 33 \\
\hline 44 & Sara & $\begin{array}{l}\text { Batista Independen- } \\
\text { te, em Contagem }\end{array}$ & 227 & Contagem & $\begin{array}{l}\text { João Mon- } \\
\text { levade }\end{array}$ & 553 & 332 & 33 \\
\hline 55 & $\begin{array}{l}\text { Ra- } \\
\text { quel }\end{array}$ & $\begin{array}{l}\text { Batista Independen- } \\
\text { te, em Contagem }\end{array}$ & 115 & Contagem & $\begin{array}{l}\text { Belo Hori- } \\
\text { zonte }\end{array}$ & 551 & 331 & 11 \\
\hline 66 & Ana & $\begin{array}{l}\text { Batista Independen- } \\
\text { te, em Contagem }\end{array}$ & 113 & Contagem & $\begin{array}{l}\text { Belo Hori- } \\
\text { zonte }\end{array}$ & 446 & 226 & 22 \\
\hline 77 & Raabe & $\begin{array}{l}\text { Batista Independen- } \\
\text { te, em Contagem }\end{array}$ & 110 & Contagem & Contagem & 441 & 220 & 22 \\
\hline Média & & & 118,5 & - & - & 449 & 227 & 22,4 \\
\hline
\end{tabular}

Fonte: Quadro elaborado a partir das entrevistas.

A idade média das nossas entrevistadas é de 49 anos, sendo que o tempo médio de matrimônio é de 27 anos, com média de 2,4 filhos(as). Todas as entrevistadas são oriundas do Estado de Minas Gerais, sendo que a naturalidade de $58 \%$ é de Belo Horizonte. Não obstante, percebemos um êxodo, afinal, $72 \%$ residem na cidade metropolitana de Contagem. Apenas a entrevistada Raabe é natural e reside em Contagem. Rute reside em Sabará. Assim, nosso eixo de pesquisa foi Belo Horizonte, Contagem e Sabará - todos munícipios de Minas Gerais.

Acerca da escolaridade, percebemos que $43 \%$ das entrevistadas têm primeiro grau incompleto, $43 \%$ segundo grau completo, e $14 \%$ estão 
graduando em Teologia - escolha de curso priorizada pela fé professada. Confrontando a escolaridade das entrevistadas com o perfil nacional de educação, em 2015, conforme Gráfico 1, notamos uma semelhança entre os dados nacionais e os identificados em nossa pesquisa. A maior concentração de mulheres tem entre 1 a 14 anos de estudo, sendo seguido por 15 ou mais anos de estudo. Não foram identificadas mulheres sem instrução.

Gráfico 1 - Distribuição das pessoas por sexo, grupos de anos de estudo - Brasil 2015

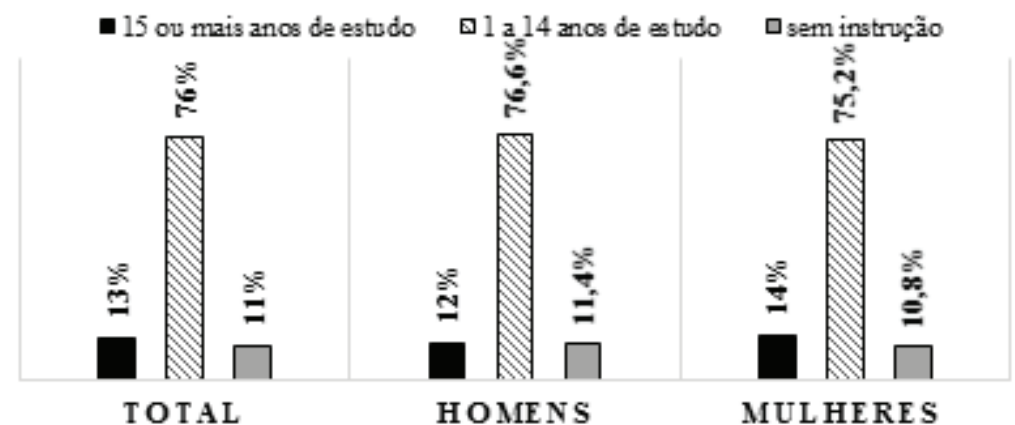

Fonte: IBGE, Diretoria de Pesquisas, Coordenação de Trabalho e Rendimento, Pesquisa Nacional por Amostra de Domicílios 2015.

No que se refere ao perfil econômico, consideramos a renda das entrevistadas e, posteriormente, a renda de toda a família (incluso das mulheres), conforme Gráfico 2 e 3 respectivamente.

Gráfico 2 - Renda das entrevistadas

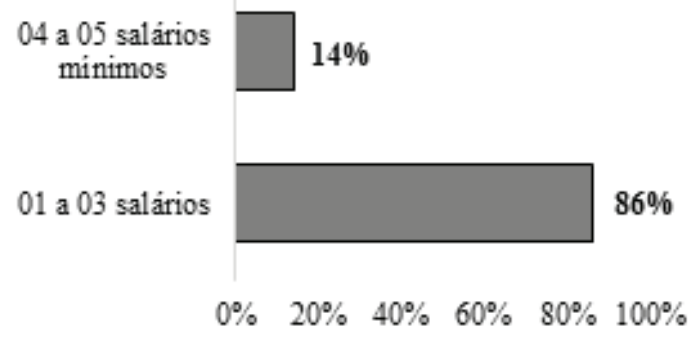

Fonte: Entrevistas. 
Gráfico 3 - Renda total familiar

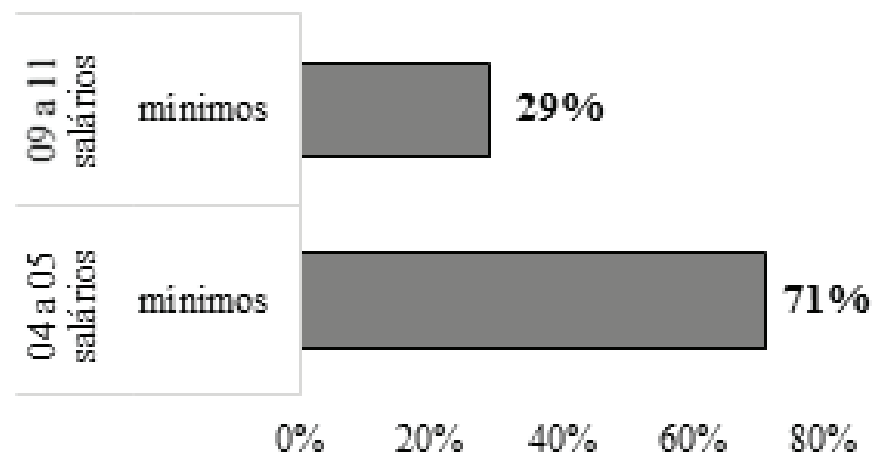

Fonte: Entrevistas.

Notamos dos índices que $86 \%$ das entrevistadas auferem entre 01 0 03 salários mínimos vigentes. ${ }^{17}$ Apenas a entrevistada Glória aufere entre 04 e 05 salários mínimos vigentes. Considerando a renda total familiar, 71\% das famílias têm renda entre 04 e 05 salários mínimos vigentes. Portanto, a maior fonte de renda nas famílias das entrevistadas é proveniente das mulheres. De acordo com o Instituto Brasileiro de Geografia Estatística (IBGE), ${ }^{18}$ em Minas Gerais o rendimento nominal mensal domiciliar per capita da população residente em Minas Gerais, em 2016, foi de $\mathrm{R} \$ \mathbf{1 . 1 6 8 , 0 0}$ e, no Brasil, de $\mathrm{R} \$ 1.226$,00. Logo, o perfil econômico das entrevistadas coincide com o cenário estadual e nacional respectivamente, os quais apontam para a famigerada pobreza nacional. A ausência de casa própria, que perpassa nossas entrevistadas, é um indício evidente dessa escassez econômica.

Acerca da fecundidade, ${ }^{19}$ nossas entrevistadas têm média de 2,4 filhos. No Sudeste, em 1990, a média era de 2,36 filhos(as). Logo, obser-

Nos termos da Lei $n^{\circ}$. 13.152, de 29 de julho de 2015, considera-se para 2017 o valor de R\$937,00.

18 Disponível em ftp://ftp.ibge.gov.br/Trabalho_e_Rendimento/Pesquisa_Nacional_por_Amostra_de_Domicilios_continua/Renda_domiciliar_per_capita/Renda_domiciliar per_capita_2016. pdf. Acesso em 17 ago. 2017.

19 A taxa de fecundidade indica quantos filhos, em média, tem a mulher brasileira. Disponível em http://7a12.ibge.gov.br/vamos-conhecer-o-brasil/nosso-povo/nupcialidade-e-fecundidade.html. Acesso em 17 ago. 2017. 
vando aquele contexto histórico oportuno, concluímos que a fecundidade das entrevistadas está ajustada ao perfil da região naquela década.

Lembramos que $100 \%$ das entrevistadas são casadas, embora esse não tenha sido um requisito da pesquisa. O casamento é uma instituição civil e religiosa muito representativa, decorrente do perfil majoritariamente cristão do país, afinal, mais de $80 \%$ da população se declara cristã. ${ }^{20} \mathrm{O}$ alto índice de nupcialidade nacional é coerente com o identificado em nossa pesquisa. Da mesma forma, o baixo índice de rompimento conjugal no país [separados judicialmente e divórcio] de $7,8 \%$, é coerente com nossa pesquisa, na qual apenas duas entrevistadas estão divorciadas/separadas. Em se tratando do divórcio, ${ }^{21}$ na perspectiva das entrevistadas, $57 \%$ afirmaram que não se divorciariam devido à violência doméstica e $43 \%$ declararam que se divorciariam, embora não tenham se divorciado. O divórcio é tema ainda controverso entre cristãos protestantes e pentecostais, ainda que não seja considerado um sacramento, diferente do catolicismo, que mantém essa crença. ${ }^{22}$ Nesse sentido, $100 \%$ afirmaram que não perderiam a salvação, tampouco estariam cometendo pecado, caso optassem pelo divórcio. Ao que parece, a justificativa para a manutenção do casamento não está assentada no discurso religioso das entrevistadas. Talvez esteja assentado na frágil situação financeira e ausência de moradia, evidenciados nos aspectos sociais deste estudo, ou ainda, em aspectos de natureza psicológica que extrapolam o objetivo deste trabalho.

Além disso, aspectos oriundos da construção social, que relaciona os homens ao espaço público, ao poder e dominação, e, às mulheres ao espaço privado e à submissão foram observados na pesquisa. A

20 Conforme Censo IBGE 2010. Disponível em https://censo2010.ibge.gov.br/noticias-censo.htm I? view $=$ noticia\&id=3\&idnoticia $=2170 \&$ busca $=1 \& \mathrm{t}=$ censo-2010-numero-catolicos-cai-aumenta-evangelicos-espiritas-sem-religiao. Acesso 23 nov. 2017.

21 A Lei do Divórcio no Brasil data de 26 dezembro de 1977. Segundo o IBGE (2015), em 1984, foram contabilizados 30,8 mil divórcios. Em 1994, foram registrados 94,1 mil casos, representando um acréscimo de $205,1 \%$ em relação a 1984 . Em 2004, com 130,5 mil casos, o aumento foi de $38,7 \%$. Na comparação entre 1984 e 2104, no entanto, o crescimento é de $1.007 \%$. Site: http://www. brasil.gov.br/cidadania-e-justica/2015/11/em-10-anos-taxa-de-divorcios-cresce-mais-de-16o-no-pais. Acesso em 16 de maio de 2017.

22 Para maiores detalhes, http://www.vatican.va/archive/cathechism_po/index_new/p2s2cap1_1210-1419 po.html. Acesso em 23 jul. 2017. 
submissão, no entanto, se funda em elementos diversos, entre os quais citamos: construção social, perfil social das entrevistadas, convicções religiosas e relações de gênero. Tais elementos definem um lugar a ser ocupado. Aduz Sandra Duarte de Souza (2009):

Esse lugar da mulher na sociedade não é um lugar natural, mas construído socioculturalmente num contexto cultural patriarcal. A mudança da situação de violência de gênero passa necessariamente pela superação desse imaginário da subordinação natural das muIheres, produzindo e reproduzindo pelos mais diversos mecanismos de produção de significado (Sandra Duarte de SOUZA, 2009, p. 35).

Tal comportamento social está atrelado ao aspecto cultural, que se manifesta em comportamentos, condutas essas que movem a sociedade. Segundo Peter Berger (2013):

A cultura é objetiva por se defrontar ao homem como um conjunto de objetos do mundo real existente fora de sua consciência. A cultura está lá. A cultura lá está à disposição de qualquer um (Peter BERGER, 2013, p. 23).

Desponta como urgente uma mudança de paradigma de gênero que paute não por hierarquias, mas pela igualdade entre humanos, que remodele alguns aspectos socioculturais. Essa mudança obviamente passará por um processo que privilegie os direitos humanos, e, por conseguinte, as relações equânimes entre gêneros, raças, etnias e religiões. Essa perspectiva envolve uma ressignificação política, social, econômica, religiosa, e por que não, cultural. Nesse novo contexto, a violência deixaria de gozar de certa naturalidade. Para Maria Clara Bingemer (2001):

Talvez a mais diabólica vitória da violência seja não deixar ninguém de fora de seu envolvimento tentacular, não podemos deixar de perceber, necessariamente, que estamos todos implicados. Somos todos[as] vítimas de uma história patológica. E o segredo para que haja uma "cura" coletiva, um processo solidário de cura, é conscientizar-se desse processo e assumir que estamos todo doentes deste mal, ou pelo menos deles convalescendo (Maria Clara BINGEMER, 2001, p. 12). 
Nesse sentido, o exercício da violência não seria compreendido como ato passional, afinal a alteridade é atributo do amor, não a violência. Age-se violentamente em decorrência de um envenenamento prévio de anseio por poder e dominação. A síntese desses elementos destila violência, desigualdades e segregações.

As mulheres, por séculos, ocupam predominantemente esse lugar de segregação, designado por critério de gênero. Ao serem indagadas sobre a igualdade de gênero, 100\% das entrevistadas afirmaram que na sociedade não há igualdade. Isso pois numa disputa social de poder nas relações de gênero, há dominação e não equiparação. Assim, numa estrutura androcêntrica, os homens predominantemente dominam. Sem equiparação de direitos entre sujeitos, não há que se falar em igualdade e sim em poder exercido e subordinação desempenhada. Conforme Pierre Bourdieu (2002):

A dominação masculina, que constituiu as mulheres como objetos simbólicos, cujo ser (esse) é um ser-percebido (percipi) tem por efeito colocá-las em permanente estado de insegurança corporal, ou melhor. De dependência simbólica: elas existem primeiro pelo, e para o olhar dos outros, ou seja, enquanto objetos receptíveis, atraentes, atraentes e disponíveis. Delas se espera que sejam "femininas", isto é, sorridentes, simpáticas, atenciosas, submissas, discretas, contidas ou até mesmo apegadas (Pierre BOURDIEU, 2002, p. 96).

O amadurecimento das construções sociais, que contemple também a perspectiva de gênero, favorecerá uma melhor compreensão das relações de poder e dominação que perpassa a sociedade, no sentido de uma nova configuração que privilegie a humanidade e sua dignidade. Para Ivone Gebara (2000):

A categoria de Gênero ajuda a perceber a dinâmica das relações e dos poderes, mas ela não pode ser considerada como conceito absoluto, capaz de explicar toda a opressão das mulheres. Se somos contra o fetichismo da virilidade, não podemos erigir Gênero em novo fetichismo. Se somos contra os discursos totalitários, não podemos erigir um conceito em chave explicativa da totalidade. Portanto, é preciso resguardar sempre a dialética das relações homens/mulheres, tendo em vista que a vida humana se desenrola na interação contínua entre 
os dois sexos, apesar das injustiças históricas que sofremos [mulheres] (Ivone GEBARA, 2000, p. 114, grifos do autor).

Não obstante, manter uma construção histórica que tenha favorecido a desigualdade, incluso nas relações de gêneros, é manter a usurpação de liberdade, segregação e violência. A exclusão, qualquer que seja, priva a liberdade. Sob vários aspectos, é necessário emancipação. Dessa forma, num recorte de gênero, revela-se necessário que as mulheres, como sujeitas históricas, se movimentem rumo à emancipação, como aduziu Joan Scott (2013) em entrevista à revista Mandrágora realizada pela professora Fernanda Lemos:

Se você usa o gênero como uma ferramenta crítica expondo não só o fato da presença das mulheres na história, mas as razões para sua invisibilidade ou marginalização da política, e da vida pública, então você está avançando na "causa" da emancipação das mulheres (Joan SCOTT, 2013, p. 163).

Esse processo emancipatório das mulheres se inicia pela constatação das graves infrações aos direitos humanos dessas sujeitas que são históricas, mas que foram ignorados por árduos anos. Essas premissas provocam um movimento na ordem social estabelecida. Todavia, ressaltamos que não se trata de disputa de poder ou inversão hierárquica, mas sim, de emancipação e igualdade de direitos. Em outros termos, de equivalência humana entre toda a humanidade, incluindo na categoria de gênero.

Por fim, consideramos que esse movimento de emancipação das mulheres não foi evidenciado na violência doméstica experienciada pelas pentecostais entrevistadas, ao contrário, foi percebido uma acomodação de natureza social e religiosa.

Em síntese, as entrevistadas fazem parte de um cenário de dominação masculina, de pobreza, de violência doméstica e de religiosidade. Logo, aspectos sociais e econômicos foram percebidos na violência doméstica experienciada pelas entrevistadas, seja na causa da violência, seja na permanência da situação de violência experienciada. 


\section{ASPECTOS RELIGIOSOS DA VIOLÊNCIA DOMÉSTICA EM ESTUdO}

Buscamos compreender o significado e a importância da pertença pentecostal e de Deus na vida e nos discursos das mulheres entrevistadas. Lembramos que o tempo médio de pertença pentecostal das entrevistadas é de 18,5 anos. Nesse cenário pentecostal, tivemos mais de $80 \%$ das entrevistadas declarando vínculo com alguma igreja de origem batista, porém pentecostal. A esse respeito, consideramos as elucidações de Antônio Gouvêa Mendonça (1990):

Poderíamos tentar classificar os pentecostais brasileiros de diversos modos, tais como: historicamente, isto é, pelos períodos de surgimento ou implantação, pelas suas origens eclesiásticas; pelos traços doutrinários e de governo eclesiástico, etc. Como por exemplo (...) 2. Pentecostais recentes inclui-se, Batista independente, Metodista Weslyana Presbiteriana Renovada, Assembleia de Deus Presbiteriana (Antônio Gouvêa MENDONÇA, 1990, p. 21).

Dessas igrejas denominadas por Antônio Gouvêa de Mendonça como pentecostais recentes, temos $57 \%$ de igrejas batistas pentecostais situadas em Contagem, 14\% igrejas batistas pentecostais situadas em Belo Horizonte. Além disso, 14\% são da Assembleia de Deus, situadas em Belo Horizonte. As lideranças pastorais das igrejas frequentadas pelas entrevistadas são predominantemente de mulheres, com $57 \%$, seguidos de $29 \%$ de homens, e, em $14 \%$ uma pastora e um pastor lideram conjuntamente - embora tenha sido pontuado que a pastora parece liderar em maior escala.

A respeito do percurso religioso das entrevistas, antes de afirmarem pertença pentecostal, 71\% se declaravam católicas: Glória, Raquel, Ana, Raabe e Rute, que além de católica, teve também um período na umbanda. Débora, correspondente a 14\%, se disse sempre pentecostal, enquanto Sara, $14 \%$, era sem religião.

Os cônjuges trazem trajetória religiosa diversa, afinal, $71 \%$ das entrevistadas afirmaram que o cônjuge é sem religião; $14 \%$ disseram que o cônjuge é "católico não praticante" e 14\% disseram que o cônjuge atual²3

23 Esse cônjuge do $2^{\circ}$. casamento, foi definido pela entrevistada como alguém que não pratica violência doméstica. 
é protestante da Igreja Batista de origem histórica. ${ }^{24}$ Esse cenário de pertença dos cônjuges tem se mantido estanque ao longo dos anos.

Tais dados coadunam com o Censo Religioso do Brasil de 2010, no qual os sem religião são predominantemente compostos por homens, e, as mulheres tendem a serem mais religiosas. ${ }^{25}$ Nenhuma das entrevistadas afirmou participar de trânsito religioso, ou seja, mobilidade entre confissões religiosas. Ao contrário, as mulheres entrevistadas declararam exclusividade ao cristianismo com pertença unicamente pentecostal.

Registramos que a percepção dessas mulheres sobre o pentecostalismo é de grande relevância, pois afirmam que lhes proporciona bem-estar, além de "libertação de vícios". Esses discursos nos dão pistas de como a pertença pentecostal pode ser proeminente na vida dessas mulheres.

Débora (2017) ótimo [ser pentecostal]!! Me proporcionou uma mudança de vida. O meu Deus é um socorro. Sem Deus, não sei como teria sido esses anos todos.

Glória (2017) eu amo ser pentecostal!

Rute (2017) sei discernir o certo do errado. Rejeitar o que não condiz. Ajuda a colocar o "pé no freio", porque o "erro" não tem aceitação coletiva e a punição vem com perda de cargo etc.

Sara (2017) minha fé vem da religião. Sem a fé, não há avanço. Raquel (2017) me faz feliz e é muito importante para mim.

Ana (2017) muito bom ser evangélica, eu bebia e fumava. Hoje eu não tenho mais vícios. Foi através da igreja e do batismo que eu fui liberta. Raabe (2017) é positivo, me traz calma em casa e me ajuda a lidar com a situação com minha sogra que é constantemente desafiante.

Acerca da liderança religiosa, 71\% afirmaram que compartilharam a violência doméstica com alguma liderança, e $29 \%$ disseram que nunca compartilharam. Muitas das mulheres que compartilharam foram indagadas sobre qual conselho receberam, ao que disseram:

24 MENDONÇA, Antônio Gouvêa. Introdução ao Protestantismo no Brasil. São Paulo: Edições Loyola,1990, p. 47.

25 Censo 2010. Disponível em https://cens02010.ibge.gov.br/noticias-censo. Acesso em 27 set. 2017. Para detalhes ver VIERA, José Álvaro Campos. Aurora de uma espiritualidade sem religião: análise dos sem religião a partir da concepção de espiritualidade não religiosa de Marià Corbí do PPCR PUCMG. Disponível em http://www.sistemas.pucminas.br/BDP/SilverStream/Pages/pg Consltem.html. Acesso em 28 nov. 2017. 
Débora (2017): vieram o pastor e um líder e falaram com meu marido. Me aconselharam a aguentar, pois os filhos eram crianças, e, ele ainda iria se converter e melhorar. Também disseram que uma mulher jovem e separada, não era bem vista na igreja.

Glória (2017): o pastor falou que a situação era caso de polícia.

Rute (2017): eu tive conselho, mas não tive apoio.

Sara (2017): o pastor falou para eu tolerar, como Deus ensinou.

Raquel (2017): a pastora falou para eu conversar com ele, e levá-lo para a igreja. A pastora chegou a fazer um culto no meu lar, mas, ao final disse que eu precisava mudar. Ainda penso no que ela quis dizer com isso. Ela também sugeriu levá-lo para uma casa de recuperação para alcoolismo.

Destarte, a maioria das lideranças religiosas citadas pelas entrevistadas apresentou um discurso de submissão da mulher e de esperança na conversão dos maridos para redenção da violência doméstica. Os discursos das lideranças religiosas parecem atrelar uma vida conjugal sem violência ao discurso salvífico dos cônjuges. A conversão dos maridos seria o benefício decorrente do autossacrifício - tolerância por parte das mulheres. Em 100\% das entrevistadas, foram constatadas reincidência da violência doméstica. Segundo Ivone Gebara (2000, p. 196), “[...] o mal é aceitar o destino de oprimido/a, sem lutar pela própria dignidade. O mal é calar-se quando é preciso denunciar as injustiças". Porém, no cenário pesquisado, calar-se e ser oprimida parece compreendido como oportuno ao fim almejado - conversão dos cônjuges.

Dessa forma, buscamos verificar se as entrevistadas seguiram os conselhos da liderança religiosa, e 57\% afirmaram que seguiram em algum momento, $29 \%$ disseram que não seguiram os conselhos em momento algum, e 14\% declararam que não receberam conselhos da liderança religiosa, pois nunca abordaram a violência doméstica experienciada. A maioria seguiu os conselhos da liderança em algum momento e medida. Nessa esteira, compreendemos que a opinião da liderança religiosa foi requerida pelas entrevistadas em assuntos relativos ao matrimônio e família. A liderança religiosa ocuparia não apenas local de destaque na igreja e nos assuntos de fé, mas, é também impelida a opinar nos assuntos da vida privada das entrevistadas. 
Salientamos que os discursos das lideranças coincidem com o discurso das próprias mulheres acerca das tratativas frente à violência doméstica experienciada, que de forma sintetizada seria: conversão dos cônjuges para mudança de vida. A força da religião, ou ainda, da pertença pentecostal na realidade cotidiana das entrevistadas, é notada como difusa e preponderante. Nesse sentido, aduz Sandra Duarte Souza:

[...] a religião exerce uma importante função de produção e reprodução de sistemas simbólicos que têm uma influência direta sobre as relações sociais de sexo. [...] Os sistemas religiosos são sistemas de sentido, construindo uma cosmovisão generificada orientadora de seus seguidores e seguidoras (Sandra Duarte de SOUZA, 2009, p. 61).

A religião tem impacto na produção de sentidos. A relevância dessa constatação é importante, entre outros motivos, pelo fato de Minas Gerais ter uma considerável população de evangélicos pentecostais. Ademais, lembramos, $22 \%$ do país se declaram evangélicos, e a maior parte é de pentecostal.

Gráfico 4 - População residente Sudeste: Evangélicos de origem pentecostal

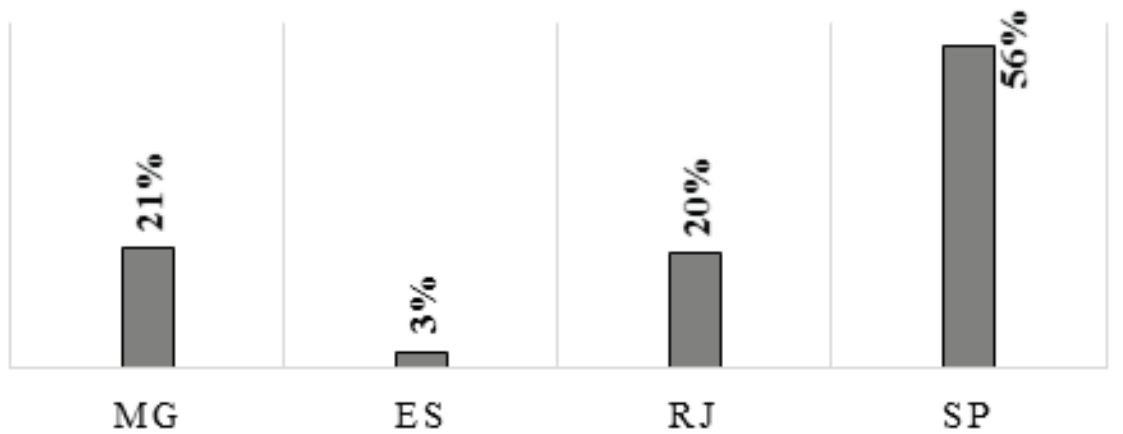

Fonte: IBGE - Censo Religiões $2010^{26}$

26 https://ww2.ibge.gov.br/estadosat/temas.php?sigla=mg\&tema=censodemog2010_relig. Acesso 20 nov. 2017. 
A Região Sudeste, São Paulo, Minas Gerais e Rio de Janeiro, nessa ordem, são os três Estados mais populosos do Sudeste, conforme o IBGE. Assim, Minas Gerais ocupar a $2^{\mathrm{a}}$. posição em número de pentecostais no Sudeste é um dado relevante. Afinal, $21 \%$ dos mineiros são pentecostais. O ethos social mineiro atual traz, em grande medida, a pertença pentecostal. Conforme Carolina Teles Lemos (2013):

A religião, enquanto sistema simbólico que contém e expressa ethos de uma população, interage, de maneira dialética, com uma das destacadas características socioculturais de nossa história: o patriarcado (Carolina Teles LEMOS, 2013, p. 201).

Dada a essa força da religião, focamos compreender se a violência doméstica foi, ou tem sido, tema de pregação pelas lideranças religiosas nas igrejas, e $71 \%$ das entrevistadas afirmaram que nunca houve pregação sobre a violência doméstica na igreja; $14 \%$ declararam que houve pregação, e 14\% não se lembram se houve abordagem ao tema. Acerca do teor da pregação ministrada sobre a temática, Ana (2017) esclareceu: "na pregação a pastora dizia que a mulher deve ser sábia e "levar" o marido para a igreja. Enquanto isso é preciso aguentar". A dita orientação parece coincidir com aquela citada por Maria das Dores Campos Machado (1996 p. 194) “[...] as mulheres que aderem solitariamente às comunidades pentecostais, [...], são incentivadas pela liderança religiosa a terem uma maior tolerância com os parceiros e filhos".

As entrevistadas percebem a força da religião e especificamente da pertença pentecostal nos fiéis e, por isso, consideram importante a tratativa adequada da violência doméstica nas igrejas.

Débora (2017) alertaria as mulheres, mas, os homens iriam achar ruim, porque iria expor o lado violento deles.

Glória (2017), pode haver alguém passando por isso e achando normal. Rute (2017), pregar sobre o tema, colar cartazes, via mídia da igreja. Isso para as mulheres se encorajarem. $O$ alcance da igreja é grande. Sara (2017) poderia ajudar a evitar. Há pessoas que na igreja é crente, mas em casa, é outra pessoa.

Raquel (2017) para orientar mulheres e homens.

Raabe (2017) pode ocorrer de uma mulher querer ouvir sobre isso, e 
não há esse tipo de assunto sendo explicado. Será que entre pastores e suas mulheres são maravilhas?

Dada essa relevância da pertença perante os fiéis, nos parece oportuno a tratativa adequada da violência doméstica nas Igrejas. Nossa proposta é que discursos emancipatórios, de dignidade humana e de igualdade de direitos, substituam os tradicionais discursos androcêntrico patriarcais, proferidos também em alguns cenários religiosos. Segundo Sandra Duarte de Souza (2009, p. 65), "a partir de um discurso misógino, a religião não apenas produz ou reproduz a violência de gênero, mas a sacraliza". Isso pois, para determinadas pessoas, o discurso religioso pode perder a condição de coisa construída e ser entendido como verdade sagrada.

O viés emancipatório, via discurso e ação, necessita ser aprimorado e implementado. Afinal, objetiva a percepção e prática da singularidade entre sujeitos que se equiparam em igualdade de direitos, enquanto indivíduos da humanidade. Pertinente que tais premissas, se tornem um modelo social, aderido e absorvido pela sociedade como modo de pensar e agir socialmente e religiosamente. Conforme Peter Berger (2013):

O indivíduo não é modelado como uma coisa passiva, inerte. Ao contrário, ele é formado no curso de uma prolongada conversação, em que ele é participante. O mundo social não é (com suas instituições, papéis e identidades apropriadas), não é simplesmente absorvido pelo indivíduo, e sim apropriado ativamente por ele (Peter BERGER, 2013, p. 31).

Ademais, as entrevistadas compartilharam que na(s) igreja(s) que frequenta $(m)$, acreditam haver mulheres que tenham ou estejam experienciando a violência doméstica, porém, se silenciam. Essa inferência decorreria dos "pedidos públicos de oração pelos maridos e pelo casamento" e ainda, por situações de "violência doméstica verbal praticada em público”. Há, no contexto pentecostal, oportunidades efetivas de participação ativa no confronto à violência doméstica.

Obviamente não há, nesta pesquisa, o intuito de manifestar oposição às orações pelos cônjuges, às crenças, e aos trabalhos evangelís- 
ticos direcionados aos maridos. Acreditamos que a concretização da dignidade das mulheres e o cessamento da violência doméstica pode perfeitamente coexistir com as orações para conversão dos cônjuges.

As mulheres pentecostais, assim como quaisquer mulheres, precisam se compreender como "sujeitas históricas", cuja dignidade e direitos humanos devem ser respeitados e observados como um dos primores da vida.

Ao serem indagadas sobre passagens bíblicas que retratam as mulheres, $57 \%$ se lembraram de no mínimo uma passagem bíblica sobre mulheres, porém, foi necessário que tivessem um tempo de reflexão, não foi espontâneo. As demais, $43 \%$, não se lembraram de qualquer passagem bíblica referente às mulheres. Destacamos que, Sara, disse não se lembrar, mas, após refletir ponderou: "Salomão [rei] tinha muitas concubinas". Revelou-se evidente que a percepção das mulheres sobre as mulheres no cristianismo, ao menos entre as entrevistadas, é predominantemente patriarcal. As mulheres não ocupam lugar de fácil lembrança e destaque no imaginário religioso cristão. Essa estrutura religiosa patriarcal se revela também nos conselhos da liderança religiosa, assim como na maioria masculina exercendo a liderança das igrejas, bem como, na compreensão bíblica das relações de gênero.

Acerca da percepção de igualdade de gênero nas igrejas, apenas $14 \%$ disseram haver igualdade entre homens e mulheres, o que sugere alguma identificação pelas mulheres de sua condição de subjugação. Ao serem indagadas se haveria igualdade perante Deus, $86 \%$ afirmaram haver igualdade e $14 \%$ disseram que não há igualdade entre gêneros sendo esclarecido "há submissão bíblica das mulheres". Nesse aspecto, parece oportuno uma ressignificação das mulheres na perspectiva bíblica, e, entre outros, a teologia feminista ${ }^{27}$ poderá oferecer contribuições valiosas.

No que tange à submissão, $86 \%$ disseram que as mulheres não devem submissão aos homens/cônjuge e 14\% afirmaram que deve haver submissão. Notamos que o fato de experienciarem violência doméstica por décadas de modo reincidente, de alguma maneira expressa

27 Para maiores detalhes ver autoras: REIMER, Ivoni R.; GEBARA, Ivoni; FIORENZA SCHÜSSLER, Elisabeth; BINGEMER, Maria Clara, entre outras. 
submissão. Da mesma forma, se culparem e se autossacrificarem pela violência doméstica, conota em alguma medida submissão, ainda que as entrevistadas não percebam ou se esquivem de tal evidência. Sintetizando a situação da mulher, a teóloga Maria Clara BINGEMER (1990, p. 14) conclui: "duplamente oprimida, quando pobre e mulher. A mulher, uma vez que se compreende como aquela que começa a "desconhecer seu lugar", vai romper o silêncio".

Contudo, em nossa pesquisa, numa perspectiva de futuro, não foram identificadas nos discursos das entrevistadas afirmações no sentido de "desconhecer o lugar oprimido da mulher" e de ocupar o lugar que desejar. Ao contrário, notamos mulheres oprimidas pela pobreza e pela violência doméstica, e o discurso religioso, sobre o tema, sugere tolerância para um porvir de conversão. Nesse sentido, Maria das Dores Campos Machado (1996) corrobora:

...entre os maridos, verifiquei que a reação hostil tende a ser superada à medida que eles percebem os benefícios da afiliação religiosa. [...] E mais, se existem feitos positivos capazes de consolidar o relacionamento familiar, isto se deve mais ao fato de que a busca da santificação (preocupação comum a carismáticos e pentecostais) provoca uma mudança no comportamento do converso, do que ao esforço de transformar atitudes familiares (Maria das Dores C. MACHADO, 1996, p. 194, grifos do autor).

A relevância do discurso religioso é notória, afinal, a pertença pentecostal foi difundida pelas entrevistadas como benéfica, causa de alegria, gozo, e mais, como caminho bem-sucedido para a libertação de vícios e melhoria de comportamentos. Crendo na futura conversão dos cônjuges, algumas entrevistadas projetam suas vidas abarcando seus maridos numa realidade doméstica transformada e saudável. Essa realidade do porvir inclui residência própria, afeto conjugal e ausência de violência.

Sara (2017), ser feliz no relacionamento, no casamento.

Ana (2017) [sorri ao falar] morar em um sítio com meu marido. Meus filhos e netos me visitariam. 
Raabe (2017) as filhas maiores facilitam muito. Poderei curtir meu marido. Amo muito meu marido.

O ideal de futuro partilhado é o oposto da realidade atual das entrevistadas. Assim, as entrevistadas consolidam suas esperanças no processo de conversão dos maridos, a partir do qual mudanças benéficas que teriam experienciado em seus próprios modos de agir seriam operadas nas condutas dos cônjuges. As entrevistadas querem manter seus casamentos. Há uma esperança latente na atuação divina que resultaria em mudança na realidade terrena vivida. O discurso religioso é vigoroso e inflamado de fé. As entrevistadas encontram na pertença um bálsamo para dias difíceis. No entanto, não identificamos ações ou discursos religiosos que defrontam a violência doméstica como um ato cruel que infringe os direitos humanos e a dignidade das mulheres.

Frente ao exposto, foram identificados aspectos religiosos na violência doméstica em estudo.

\section{CONSIDERAÇÕES FINAIS}

As sete mulheres pentecostais entrevistadas experienciaram todas as formas de violência doméstica durante décadas, sendo o início da ocorrência após o casamento e de forma reincidente.

Considerando o perfil social e econômico das entrevistadas frente aos dados nacionais do IBGE, notamos similaridade com o perfil médio nacional - uma população predominantemente pobre, com pouca formação escolar e alta incidência de violência doméstica. Alguns discursos das entrevistadas sobre ausência de casa própria, difícil situação econômica, saúde debilitada com dependência de convênio custeado pelo cônjuge, frágil formação escolar e vício de alguns cônjuges como abuso de álcool, são aspectos sociais presentes nas relações familiares das entrevistadas e se repete no cenário nacional.

Os aparatos estatais como: apoio judicial, polícia e casas de amparo, não foram evidenciados na pesquisa, como sendo eficazes na perspectiva das entrevistadas, como uma forma de solução.

Além disso, o ethos social de submissão das mulheres, bem como, problemas evidentes nas relações de gênero que permeiam as relações sociais são também aspectos sociais identificados na violência domés- 
tica em análise. Por fim, a violência doméstica em estudo está eivada de aspectos sociais.

Em se tratando dos aspectos religiosos, igualmente foram identificados elementos nos discursos das entrevistadas que apontam para um agir transcendente como solução para a experiência de violência doméstica. A conversão do cônjuge à pertença pentecostal parece conotada pelas pentecostais entrevistadas como forma de encerramento da violência doméstica. Isso, pois, a conversão do cônjuge ao pentecostalismo resultaria em uma convivência familiar melhorada, sem vícios e relações extraconjugais, sem violência doméstica.

De igual modo, foi conotado que a maioria dos aconselhamentos das lideranças religiosas apontava para uma perspectiva salvífica do cônjuge por meio da paciência e sabedoria das esposas. O discurso das mulheres entrevistadas coincide com os discursos da liderança religiosa por elas compartilhados. No entanto, não foi evidenciado, a partir dos discursos das entrevistadas, que as igrejas que frequentam abordem a violência doméstica no intuito de conscientização e defrontação. As entrevistadas inferem, a partir de suas convivências, que outras mulheres frequentadoras das mesmas igrejas experienciam violência doméstica. Ao que parece, essas outras mulheres pedem orações nos cultos para a "libertação dos maridos". Frente ao exposto, aspectos religiosos foram identificados na violência doméstica em estudo.

O ethos social e religioso de submissão das mulheres resulta em desigualdade que gera problemas nas relações de gênero, entre eles a violência doméstica. Esses pressupostos representam uma afronta à dignidade das mulheres, logo, uma transgressão aos direitos humanos. Percebemos uma correlação entre aspectos sociais e religiosos na violência doméstica experienciada pelas pentecostais entrevistadas. As relações se entrelaçam como teias. A pertença pentecostal é notada como uma práxis religiosa que ressoa na práxis social. A experiência religiosa, a partir dos discursos das entrevistadas, se mostra como um modo de ver e viver a vida. Portanto, ao menos em relação às pentecostais entrevistadas, a experiência religiosa não pode ser desconectada da vida secular, tampouco desconsiderada, pois é formadora de sentido. 
Dada a importância da comunicação no pentecostalismo, o que se encontra em sua origem no Brasil, com uso de rádios, televisão etc., temos no discurso uma ferramenta de convencimento e um instrumento de mudanças. Logo, refletir e trabalhar o discurso religioso pentecostal nos parece uma via importante para mudanças na práxis religiosa e na práxis social dos(as) pentecostais.

Por fim, damos destaque à ausência de casa própria que foi acentuada em nossa pesquisa. Ter uma casa é uma necessidade humana básica, para além do mero direito de propriedade. Configura-se como ter um lugar de onde falar, um local primeiro no exercício da dignidade humana. Na pesquisa, identificamos que o fato de não terem casa própria e necessitarem residir no terreno de terceiros é causa de violência. Por isso, ao idealizarem um futuro, a casa própria emerge imperiosa entre os projetos. As entrevistadas buscam uma casa própria para nela reconstruir a vida e a história de vida. Por fim, somos todos "casas", habitando casas. Somos casa em constante construção, assim como a sociedade.

As casas que vivemos são construídas pelos sujeitos históricos que nelas habitam. As sete casas que pesquisamos são abrigo de violência e estão constantemente marcadas por tons púrpuras e escarlates. Como teias políticas, as casas são cenários que refletem a estrutura política, social, econômica, ecológica e religiosa da denominada sociedade cultural. As casas pesquisadas são oikos, mas se reverberam também em ēthos.

\section{REFERÊNCIAS}

BAUER, Martin W.; GASKELL, George. Pesquisa Qualitativa com texto, som e imagem. Petrópolis: Vozes, 2002.

BERGER, Peter. BERGER, Peter. O Dossel Sagrado. Elemento para uma teoria sociológica da religião, 9. ed. São Paulo: Paulus, 2013 [1985].

BINGEMER, Maria Clara. O mistério de Deus na mulher. Rio de Janeiro: ISER, 1990.

BINGEMER, Maria Clara Lucchetti (Org.). Violência e religião: Cristianismo, Islamismo, Judaísmo: três religiões em confronto e diálogo. Rio de Janeiro: PUC-Rio e São Paulo: Loyola, 2001.

BOURDIEU, Pierre. A dominação masculina. Rio de Janeiro: Bestbolso, 2017 [1998].

BOURDIEU, Pierre. O poder simbólico. Lisboa: Betrand Brasil, 2002 [1989]. 
BRASIL, Constituição (1988). Constituição da República Federativa do Brasil. Brasília: Senado, 1988. BRASIL, Convenção Interamericana para Prevenir, Punir e Erradicar a Violência contra a Mulher, concluída em Belém do Pará. Decreto $n^{\circ}: 1.973$ de $1^{\circ}$. de agosto de 1996. BRASIL, Censo 2010. Disponível em: <http://censo2010..ibge.gov.b>. Acesso em 13 jun. 2016.

BRASIL, Instituto de Estática e Geografia do Brasil - IBGE. Censo das religiões 2010. Disponível em https://censo2010.ibge.gov.br/noticias-censo. Acesso em 27 set. 2017.

BRASIL, Planalto. Lei $\mathbf{n}^{\circ} \mathbf{. 1 1 . 3 4 0}$ de 7 de agosto de 2006. Disponível em http://www. planalto.gov.br/ccivil_03/_ato2004-2006/2006/lei//11340.htm .Acesso em 27 set. 2017.

BRASIL, Lei Feminicídio (2015). Lei 13.104 de 9 de março de 2015. Brasília. Senado, 2015. Disponível em: <https://www.planalto.gov.br/ccivil_03/Decreto-Lei/Del2848.htm>. Acesso em: 10 jan. 2008. BRASIL, Lei Maria da Penha (2006). Lei $n^{\circ} .11 .340$, de 7 de agosto de 2006. Brasília.

BRASIL, Senado. Comissão Parlamentar Mista de Inquérito (CPMI-VCM) de 2013. Disponível em https://www12.senado.leg.br/institucional/omv/entenda-a-violencia/pdfs/ relatorio-final-da-comissao-parlamentar-mista-de-inquerito-sobre-a-violencia-contra-as-mulheres. Acesso em 27 nov. 2017.

CALLAMARD, Agnes. Entrevista Agnes Callamard. [S.I.]: ONU Brasil, jun. 2017. Entrevista concedida à ONU. Disponível em https://nacoesunidas.org/violencia-domestica-e-uma-forma-de-execucao-arbitraria-diz-especialista-independente-da-onu/. Acesso em $1^{\circ}$. nov. 2017.

FLICK, Uwe. Introdução à pesquisa qualitativa. São Paulo: Artmed. Bookman, 2009. FOUCAULT, Michel. A Ordem do Discurso: aula inaugural no Collège de France. Pronunciada em 2 de dezembro de 1970, 15. ed. São Paulo: Loyola, 2007.

GEBARA, Ivone. Rompendo o silencio. Uma fenomenologia feminista do mal. Petrópolis: Vozes, 2000.

HAGUETTE. Tereza Maria Frota. Metodologias qualitativas na sociologia, 11. ed. Petrópolis: Vozes, 1997.

LEMOS, Carolina Teles. Religião, patriarcado: elementos estruturantes das concepções e das relações de gênero. Caminhos, Goiânia, v. 11, n. 2, p. 201-2017, 2013.

LODI, João Bosco. A entrevista: teoria e prática, 2. ed. São Paulo: Pioneira, 1974.

MACHADO, Maria das Dores Campos. Carismáticas e Pentecostais, adesão religiosa na esfera familiar. São Paulo: ANPOCS, 1996.

MARCONI, Marina de Andrade, LAKATOS, Eva Maria. Técnicas de pesquisa, 7. ed. São Paulo: Atlas, 2012.

MATTAR, Fauze. N. Pesquisa de Marketing. São Paulo: Atlas, 1996.

Mandrágora, v.24. n. 1, 2018, p. 95-126 
MENDONÇA, Antônio Gouvêa. Protestantes, Pentecostais e Ecumênicos. 0 campo religioso e seus personagens. São Bernardo do Campos: Metodista, 2008.

SCOTT, Joan. Entrevista. Revista Mandrágora, São Paulo: v. 19, p. 161 -164, 2013.

SEGATO, Rita Laura. Las estruturas fundamentales de la violência. Ensayos sobre género entre la antropologia, el psicoanálisis y los derechos humanos. Argentina: Prometeo, 2010.

SELLTIZ, Writsman Cook. Método de pesquisa nas relações sociais. São Paulo: Herder. 1967.

SOUZA, Sandra Duarte de; LEMOS, Carolina Teles. A casa, as mulheres e a igreja: Gênero e religião no contexto familiar. São Paulo: Fonte Editorial, 2009.

VIERA, José Álvaro Campos. Aurora de uma espiritualidade sem religião: análise dos sem religião a partir da concepção de espiritualidade não religiosa de Marià Corbí. PPCR PUCMG. Disponível em http://www.sistemas.pucminas.br/BDP/SilverStream/Pages/ pg_Consltem.html. Acesso em 28 nov. 2017.

WAISELFISZ, Julio Jacobo. BRASIL, Mapa da Violência. Homicídio de mulheres no Brasil 2015. Disponível em http://www.mapadaviolencia.org.br/pdf2015/MapaViolencia_2015_muIheres.pdf Acesso em 27 set. 2017.

Submetido em: $24-5-2018$

Aceito em: 7-6-2018 